\title{
Latent Class Analysis of Criminal Social Identity in a Prison Sample
}

\begin{abstract}
This study aimed to examine the number of latent classes of criminal social identity that exist among male recidivistic prisoners. Latent class analysis was used to identify homogeneous groups of criminal social identity. Multinomial logistic regression was used to interpret the nature of the latent classes, or groups, by estimating the associationsto number of police arrests, recidivism, and violent offending while controlling for current age. The best fitting latent class model was a five-class solution: 'High criminal social identity' (17\%), 'High Centrality, Moderate Affect, Low Ties' (21.7\%), 'Low Centrality, Moderate Affect, High Ties' (13.3\%), 'Low Cognitive, High Affect, Low Ties' (24.6\%), and 'Low criminal social identity' (23.4\%). Each of the latent classes was predicted by differing external variables. Criminal social identity is best explained by five homogenous classes that display qualitative and quantitative differences.
\end{abstract}

Key words: Criminal Social Identity, Latent Class Analysis, Prisoners

\section{Introduction}

Social-identity reflects a particular component of an individual's overall self-concept, and is generally regarded as arising from a fundamental need to belong to a social group (Baumeister \& Leary, 1995; Tajfel, 1978; Tajfel $\&$ Turner, 1979). The development and significance of social-identity has commonly been examined in the context of religious, cultural, or demographic associations (e.g. Boatswain \& Lalonde, 2000; Cameron \& Lalonde, 2001; Obst, Smith, \& Zinkiewicz, 2002), and has only recently been specifically applied to understanding the development of a criminal identity (Boduszek \& Hyland, 2011). Boduszek and Hyland's (2011) theory of Criminal Social Identity warrants empirical investigation as it hypothesises that the development and activation of a criminal social identity will increase a person's likelihood of developing criminal thinking patterns, and subsequently engaging in criminal behaviour. Based on the conceptual and empirical work of Cameron (2004), the theory of Criminal Social Identity was constructed to reflect three related aspects of identity: (a) cognitive centrality, (b) in-group affect, and (c) in-group ties.

\section{Centrality}

The Situational Theory of Delinquency (Matza, 1964; Sykes \& Matza, 1957) postulates that criminals tend to drift in and out of non-conforming or antisocial behaviour. Under certain circumstances, such as in the company of a criminal group, individuals can be expected to think and behave in a manner that is consistent with nonconventional norms (Turjeman, Mesch, \& Fishman, 2008). Thus, antisocial behaviour is expected to be manifested only when criminal identity is salient. Saliency does not, however, require the physical presence of criminal ingroup others. Rather, the critical factor is the psychological identification with other criminal in-group members. In other words, when an individual is in proximity with noncriminal associates, their salient personal identity is likely to exhibit less anti-social/criminal attitudes than when they are in the presence of a criminal-based social group. The underlying principle is based on contextual variables, such as the salience of a given social categorization, which plays a significant part in the process of conveying the related identity to the foreground. According to Turner, Hogg,

\footnotetext{
* University of Huddersfield, UK

** University of Ulster, UK

*** Department of Behavioural and Social Sciences (R2/23), University of Huddersfield, Huddersfield, HD1 3DH, United Kingdom d.boduszek@hud.ac.uk
} 
and Oakes et al. (1987), this process refers to shifting self-categorizations or succinct modifications in the selfconcept that consequently directs psychosocial perception and conduct. Alternatively, it may be that certain individuals are persistently readier to perceive and behave in terms of a specified category than are others (Gurin \& Markus, 1989; Oakes, 1987). Thus, a criminal social identity for these people may be significantly central. Centrality is then expressed due to the cognitive accessibility of this social identification, and the operationalization of this process is reflected in the frequency with which membership of a particular social group "comes to mind".

Although a relatively new concept in social identity theory (Cameron, 2004), 'centrality' is considered to be an integral component of the theory of Criminal Social Identity as it reflects the conscious, cognitive component of belonging to a criminal group.

\section{In-Group Affect}

Research suggests that the emotive value of group membership plays an important role in Social Identity Theory (Tajfel, 1978; Tajfel \& Turner, 1979). According to this theory, individuals who have failed in their social roles and have exhibited criminal behaviour tend to see themselves as inconsistent in relation to higher level identity. Higgins (1987) suggested that such individuals experience a sense of discrepancy in terms of their actual and ideal selves which is associated with depression or a sense of agitation. In the process of identification with criminal others and forming a subgroup within the higher level of social identity, non-conforming and less successful individuals adopt the scheme of "social creativity", and according to Social Identity Theory, they achieve increased levels of self-esteem (Lemyre \& Smith, 1985; Oakes \& Turner, 1980). This is achieved through their positive distinctiveness, which is characterized by a rejection and reversal of pro-social norms. Alternatively, identification with criminal others might reduce (or even prevent from occurring) anxiety associated with the discrepancy between ought self and actual self by changing an individual's point of reference from wider societal norms to sub-group norms.

The majority of available self-report measures of social identification incorporate a number of items which directly measure the affective components of group membership (Brown, Condor, \& Matthews et al., 1986; Cameron, 2004; Ellemers, Kortekaas, \& Ouwerkerk, 1999; Hinkle, Taylor, Fox-Cardamone, \& Crook, 1989; Luhtanen \& Crocker, 1992;Phinney, 1992; Sellers, Rowley, \& Chavous et al., 1997). In the case of Criminal Social Identity theory 'in-group affect' reflects the positive emotional valence of belonging to a criminal group.

\section{In-Group Ties}

A third characteristic of social identification refers to the psychosocial ties that connect the self to a given group. Allport (1979) suggested that the identity is an "emotional merging of self with others" (p. 293). Criminal identity derives from the process of rejection and depreciation of those peers who are not associated with one's anti-social norms. Once a criminal social identity becomes established, members of the criminal group then achieve a sense of selfconsistency through a manifestation of their new identity in terms of criminal behaviours (Boduszek \&Hyland, 2011; Breakwell, 1986). Therefore, these members tend to display behaviours that are exemplary of the criminal group model and may participate with other in-group members to express their conformity (Thornberry, Krohn, \& Lizotte et al., 1993; Turner, 1982). Demonstration of overconformity to criminal standards and conduct are positively encouraged and reinforced by other in-group criminals, consequently leading to an increase in the frequency of criminal behaviour, or an alteration of non-criminal acts into criminal ones. Consequently, criminal group members do not have to apply direct persuasion in order to make an impact on another individual's antisocial attitudes or increase that person's likelihood of committing a criminal act because the necessary persuasion stems directly from the in-group ties. Empirical work conducted by Klein and Crawford (1968) and Pabon, Rodriguez, and Gurin (1992) suggests that criminal group members are characterized by a sense of belonging, which is an inter-group rather than inter-personal feature.

The character of identity as emotional ties among group members is included in most of theories of social identification (Brown et al., 1986; Cameron \& Lalonde, 2001; Hinkle et al., 1989; Phinney, 1992). In the case of Criminal Social Identity theory 'in-group ties' are reflective of the extent to which individuals feel connected to, or part of a criminal group.

\section{Criminal Social Identity Research}

In order to empirically evaluate the predictions of Criminal Social Identity theory (Boduszek \& Hyland, 2011), Boduszek, Adamson, Shevlin, and Hyland (2012) developed the Measure of Criminal Social Identity (MCSI). The MCSI is an eight item self-report measure designed to capture the three proposed factors of criminal social identity. Confirmatory factor analytic findings supported the construct validity of the scale with results indicating that the three-factor solution proposed by Criminal Social Identity theory was statistically superior to alternative and theoretically derived one- and two-factor solutions, respectively.

Subsequent to the validation of the MCSI (Boduszek et al., 2012), a series of research findings offered additional empirical support for the predictions of Criminal Social Identity theory (Boduszek \& Hyland, 2011). Despite a large body of evidence suggesting a direct link between associations with criminal peers and criminal thinking styles (Losel, 2003; Mills, Kroner, \& Forth, 2002; Mills, Anderson, \& Kroner, 2004; Sutherland, Cressey,\& Luckenbill, 1978; Sutherland, Cressey, \& Luckenbill, 1992), social identity theory predicts that prior to the acquisition of group beliefs and attitudes, a social identity should first be formed. Boduszek, Adamson, Shevlin, Hyland, and Bourke 
(2013) thus examined the proposed mediating effect of criminal social identity (Centrality, In-Group Affect, and In-Group Ties) in the relationship between associations with criminal peers and criminal thinking styles. Structural equation modelling results supported the predictions of social identity theory with findings demonstrating an indirect effect between associations with antisocial friends on criminal thinking through in-group affect and in-group ties.

In a follow-up study (Boduszek, Adamson, Shevlin, \& Hyland, 2012), in-group affect and in-group ties were again demonstrated to have a direct predictive effect on criminal thinking styles. However, in this study, the authors demonstrated that personality traits can serve to moderate the relationship between criminal social identity and criminal thinking. Specifically, moderated multiple regression analysis found that the impact of in-group affect on criminal thinking was stronger among those criminals who were more introverted, while the impact of in-group ties on criminal thinking was stronger among those criminals who were more extroverted.

Previous findings of a direct relationship between criminal social identity and criminal thinking styles are limited due to the cross-sectional nature of the study designs. In order to compensate for these limitations, and to gain a more reliable understanding of the true nature of the relationship between criminal social identity and criminal thinking, Boduszek, Shevlin, Adamson, and Hyland (2013) performed propensity score analysis with participant matching procedures which allowed for the mimicking of experimental randomization and controlling of confounding variables within a cross-sectional data set of violent and non-violent recidivistic prisoners. This procedure meant that more concrete inferences regarding the influence of an independent variable on a dependent variable in a multiple regression model could be ascertained. In this analysis, which controlled for offence type, age, extraversion, neuroticism, psychoticism, levels of recidivism, and associations with criminal friends, criminal social identity (conceptualised a composite variable) was still found to positively predict criminal thinking styles.

In addition to predicting criminal thinking styles, the relationship between criminal social identity and criminal behaviour has also been investigated. Boduszek, Hyland, Bourke, Shevlin, and Adamson (2013) found that increased levels of cognitive centrality positively predicted having committed a violent criminal offence, while increased levels of in-group affect were associated with having committed a non-violent criminal offence. These results suggest that the distinct components of criminal social identity may act as differential risk factors for various types of criminal acts.

Given the recent development of the theory of Criminal Social Identity (Boduszek \& Hyland, 2011), little empirical work exists examining the predictors of criminal social identity. In one study, associations with criminal friends were found to positively predict centrality, in-group affect, and in-group ties (Boduszek, Adamson, Shevlin, Mallett, \& Hyland, 2013). Furthermore, consistent with the predictions of Criminal Social Identity theory, higher levels of negative self-esteem were found to predict increased levels of centrality.

\section{Current Study}

Although there is consistent evidence that criminal social identity is an important predictor of criminal thinking style, comparatively little is known about the predictors of criminal social identity or the possible presence of distinct latent classes of criminal social identity. Boduszek et al. (2012) suggested a three-dimensional structure to the MCSI but more research needs to be conducted to identify whether there are different levels of criminal social identity among offenders, and what predicts membership of these particular latent classes of criminal social identity. The aim of this study is, therefore, to identify the appropriate number of latent classes with regards to criminal social identity among recidivistic prisoners, and to identify the significant predictors of each latent class of criminal social identity with aparticular focus on number of police arrests, recidivism levels, and violent offending while controlling for current age.

\section{Method}

\section{Participants and procedures}

The sample included 312 male prisoners (recidivists) incarcerated in Nowogard Maximum Security Prison. The offender sample consisted of 133 violent offenders and 179 non - violent offenders. Respondents ranged in age from 20 to 66 years $(M=33.85, S D=9.38)$. Most offenders $(88.1 \% ; n=275)$ came from urban areas. Just over half $(52.2 \% ; n=163)$ of offenders reported having primary school education, $45.5 \%(n=142)$ secondary school education, and $2.2 \%(n=7)$ some college or university. The largest proportion of participants $(68.3 \% ; n=213)$ indicated their marital status as single, $11.9 \%(n=37)$ as married, $18.6 \%(n=58)$ as divorced or separated, and 1.3\% $(n=$ 7 ) as widowed. The frequency of imprisonment reported by offenders ranged from 1 (mostly murderers) to 19 times ( $M$ $=3.57 ; S D=2.48)$ and the number of reported police arrests from 1 to $20(M=4.85 ; S D=4.09)$.

The sample was recruited over a period of 3 months (March - May, 2011), and Ethical approval for the study was granted by the Polish Prison Service. Using an opportunistic sampling strategy,362 offenders were approached. However, only 312 were considered for final analysis due to substantial missing data. Participants completed anonymous, self-administered, paper-and-pencil questionnaires which were compiled into a booklet along with an instruction sheet and a consent form attached to the front of the booklet. Each participant was provided with a brief description of the study including the general area of interest, how to complete the questionnaire, and the general expected completion time. Participants were assured about the confidentiality of their participation and informed that they could withdraw from the study at any time. Participants completed the questionnaires within the prison in their 
living units. The participation was voluntary without any form of reward.

\section{Measures}

The Measure of Criminal Social Identity (MCSI -Boduszek et al., 2012) used for this study consists of eight items and is based on Cameron's (2004) Three-dimensional Strength of Group Identification Scale. Each item on the MCSI is scored on a 5-point Likert scale (1=strongly disagree to $5=$ strongly agree). Scores range from 8 to 40 , with higher scores reflecting higher levels of criminal social identity. The first three items on the scale reflect cognitive centrality (e.g. "Being a criminal is an important part of my self-image"), the next two items reflect in-group ties (e.g. "In general I am glad to be part of a criminal group") and the last three items reflect in-group affect (e.g. "I have a lot in common with other people who committed a crime"). For the present study, items were dummy coded with 1-3 indicating a lack of item endorsement and 4 and 5 indicatingitem endorsement.

A demographic Questionnaire assessed respondents' age, location (urban, rural), education, relationship status, number of arrests, type of crime. Additionally, recidivism was estimated on the frequency of continual criminal behaviour ("How many times have you been in prison?").

\section{Analysis}

Using SPSS 20 descriptive statistics were performed for age, number of arrests, recidivism, and criminal social identity of offenders. Latent class analysis was conducted using Mplus 6.12 (Muthen \& Muthen, 2010), and was used to determine the number and nature of criminal social identity groups based on endorsement of the eight MCSI items. Six latent class models were tested (a one-through to a six-class latent class model). Selection of the optimal number of latent classes was based on several statistical fit indices. The statistical fit indices were: likelihood ratio chi-square (LR $\chi^{2}$ ), Akaike information criterion (AIC), Bayesian information criterion (BIC), sample size adjusted BIC (SSABIC), the Lo-Mendell- Rubin's adjusted likelihood ration test (LRT), and entropy measures. A non-significant LR $\chi^{2}$ indicates acceptable model fit. The information statistics AIC, BIC, and SSABIC are goodness of fit measures used to compare competing models; lower observed values indicate better fit. The LRT statistic was used to compare models with differing numbers of latent classes; a non-significant value $(p>.05)$ suggests that the model with one fewer class should be accepted. Entropy is a standardised measure of how accurately participants are classified. Values range from 0 to 1 with higher values indicating better classification.

Multinomial logistic regression was used to assess the association between class membership (posterior probabilities from the model were used to assign individuals to a class) and the number of police arrests, recidivism levels, and violent offending while controlling for current age. The subsequent odd ratios (OR) indicate the expected increase/decrease in the likelihood of scoring positively on a given variable compared to the reference, or control group (in this case the low criminal social identity group).

\section{Results}

\section{Descriptive statistics}

Table 1 presents the descriptive statistics for age, number of arrests, recidivism, and criminal identity(along with its subscales), including means $(M)$ and standard deviations $(S D)$. These statistics show that offenders demonstrate relatively moderate levels of criminal social identity across cognitive centrality, in group ties and in group affect.

Table 1. Descriptive statistics for variable included in the study

\begin{tabular}{lccccc}
\hline Scale & $M$ & $S D$ & Range & $\begin{array}{c}\text { Possible } \\
\text { Range }\end{array}$ & $\begin{array}{c}\text { Cronbach's } \\
\text { Alpha }(\alpha)\end{array}$ \\
\hline $\begin{array}{l}\text { Age } \\
\text { Number of } \\
\text { arrests }\end{array}$ & 33.85 & 9.38 & $20-66$ & --- & --- \\
$\begin{array}{l}\text { Recidivism } \\
\text { Criminal }\end{array}$ & 3.57 & 4.09 & $1-20$ & --- & --- \\
$\begin{array}{l}\text { Identity } \\
\quad \text { Centrality }\end{array}$ & 21.41 & 6.49 & $8-38$ & $8-40$ & .86 \\
$\quad \begin{array}{l}\text { In-group } \\
\text { Affect }\end{array}$ & 4.05 & 2.14 & $2-10$ & $2-10$ & .92 \\
$\begin{array}{l}\text { In-group } \\
\text { Ties }\end{array}$ & 8.67 & 3.12 & $3-15$ & 3.15 & .92 \\
\hline
\end{tabular}

Table 2 (see page 196) presents the rates of endorsement for each of the eight Criminal Social Identity (CSI) items for the entire sample after list-wise deletion. Endorsement rates were relatively low for items such as: 'having a lot in common with other people who have committed a crime' (28.5\%) and 'finding it difficult to form a bond with other people who have committed a crime' (26.9\%); both items appear under the in-group ties submeasure. By contrast, items relating to in-group affect, 'being glad to be part of a criminal group' $(69.9 \%)$ and 'feeling good when thinking about being a criminal' (67\%), were endorsed by quite a large proportion of the sample. 
Table 2. Frequency of endorsement of the Criminal Social Identity items

\begin{tabular}{lcc}
\hline Item & Yes & 110 \\
\hline Cognitive Centrality & 35.3 \\
Q1. Being a criminal has little to do with how I feel about myself in general & 122 & 39.1 \\
Q2. Being a criminal is an important part of my self-image & 111 \\
Q3. The fact I am a criminal rarely enters my mind. & 35.6 \\
In-group Affect & 209 \\
Q4. In general I'm glad to be a part of criminal group & 69.9 \\
Q5. Generally I feel good about myself when I think about being a criminal & 67 \\
In-group Ties & 119 \\
Q6. I have a lot in common with other people who committed a crime & 84 \\
Q7. I feel strong ties to other people who committed a crime & 28.5 \\
Q8. I find it difficult to form a bond with other people who committed a crime & 38.1 \\
\hline
\end{tabular}

Table 3. Fit indices for the latent class analysis of the Measure of Criminal Social Identity

\begin{tabular}{|c|c|c|c|c|c|c|c|c|}
\hline Model & $\operatorname{LR} \chi^{2}(\mathrm{df})$ & $p$ & AIC & $\mathrm{BIC}$ & SSABIC & LRT & $p$ & Entropy \\
\hline 2 classes & $\begin{array}{c}662.64 \\
(238)\end{array}$ & .00 & 2611.86 & 2675.49 & 2621.57 & 568.88 & .00 & .935 \\
\hline 3 classes & $\begin{array}{c}432.96 \\
(228)\end{array}$ & .00 & 2408.73 & 2506.05 & 2423.58 & 216.93 & .00 & .932 \\
\hline 4 classes & $\begin{array}{c}270.10 \\
(219)\end{array}$ & .01 & 2264.82 & 2395.82 & 2284.81 & 158.84 & .00 & .949 \\
\hline 5 classes & $\begin{array}{c}149.60 \\
(210)\end{array}$ & .99 & 2162.18 & 2326.87 & 2187.32 & 118.35 & .00 & .946 \\
\hline 6 classes & $\begin{array}{c}115.58 \\
(202)\end{array}$ & 1.00 & 2136.79 & 2335.17 & 2167.08 & 42.56 & .00 & .954 \\
\hline
\end{tabular}

\section{Latent class analysis of MCSI}

The fit indices for the latent class analysis are presented in Table 3. The five-class solution is considered to be the best model; LR $\chi^{2}$ is non-significant and the information statistic (BIC) is marked lower than 1,2,3, 4 and 6 class solution. Most importantly, the Lo-Mendell-Rubin's LRT indicates that the 6 class model is not significantly better than the 5 class model, therefore the 4 class solution is preferred on the basis of parsimony. The entropy value (.946) indicates very good participant classification.

Figure 1 (see page 197) shows the latent class profile plot for criminal social identity. Class five was considered to be the baseline or reference group and consisted of $23.4 \%$ of the sample. This class was characterised as having very low scores across all items of MCSI. This class was labelled 'Low criminal social identity'. Class one (17\%) was characterised by very high scores across all items of MCSI. This class was labelled 'High criminal social identity'. Class two (21.7\%) was still characterised as being a high criminal social identity group, individuals included in this sample scored particularly high on cognitive aspects of MCSI, moderately on in-group affect and very low on in group ties. This class was labelled 'High Centrality, Moderate Affect, Low Ties'. The smallest class was class three, consisting of $13.3 \%$ of the sample. Individuals in this class generally score very low on cognitive aspects, moderately on in group affect and high on in group ties. This class could be observed as being the opposite of class two. This class was labelled 'Low Centrality, Moderate Affect, High Ties'. Finally, the largest class was class four (24.6\%) and was characterised as having very low scores on cognitive aspects of MCSI and in-group ties, but very high scores on in-group affect. This group was labelled 'Low Cognitive, High Affect, Low Ties'.

Associations between the latent classes of MCSI, age, number of police arrests, recidivism and violent offending were estimated using multinomial logistic regression model. Table 4 (see page 197) presents the odds ratios attributed to each variable for each latent class in comparison to class five(the reference category).

There was no significant effect for age across any of the classes. Number of arrests was significant for Class 1 (High criminal social identity group) and Class 4 (Low Cognitive, High Affect, High Ties) comparing to reference category (Low criminal social identity group - Class 5). Individuals in these groups were significantly more likely to be arrested than individuals in Low criminal social identity class. Recidivism had a negative effect on criminal social identity for participants in the High criminal social identity group (Class 1) and Low Cognitive, High Affect, Low Ties (Class 4) classes. Finally, violent offenders were over 2times more likely to be in Class4 (Low Cognitive, High Affect, Low Ties)compared to offenders in Low criminal social identity class (Class 5). 
Figure 1. Latent class profile plot of criminal social identity

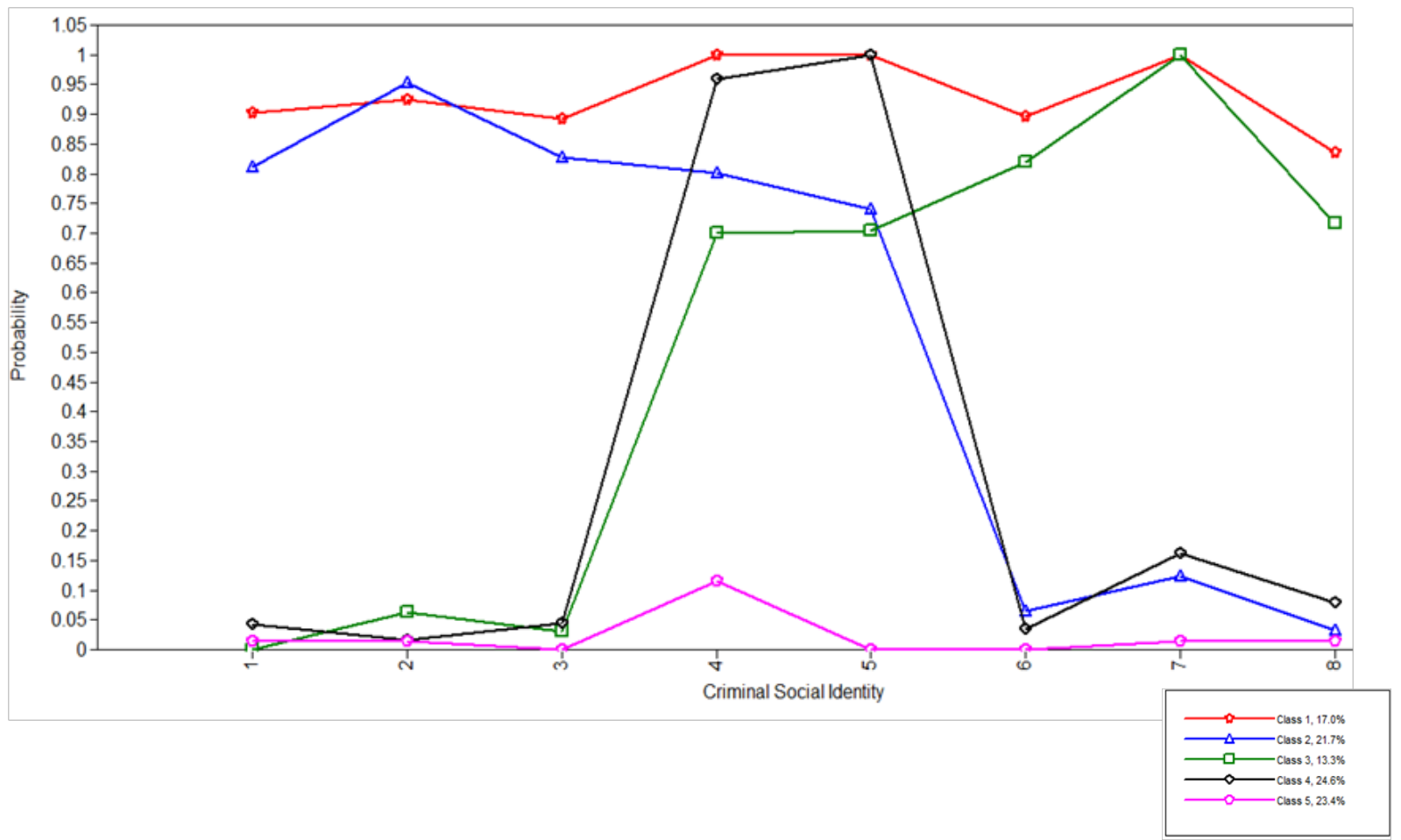

Table 4. Associations between criminal social identity classes and age, number of police arrests, recidivism, and violent offending

\begin{tabular}{lcccccccccccc}
\hline \multirow{2}{*}{ Variable } & \multicolumn{3}{c}{ Class 1 } & \multicolumn{3}{c}{ Class 2 } & \multicolumn{3}{c}{ Class 3 } & \multicolumn{3}{c}{ Class 4 } \\
\cline { 2 - 14 } & $B S E$ & OR & & $B S E$ & OR & & $B S E$ & OR & & $B S E$ & OR \\
\hline Age & .02 & .02 & 1.02 & -.03 & .02 & .97 & .03 & .02 & 1.03 & -.01 & .02 & .99 \\
Number of arrests & .16 & .07 & $1.17^{*}$ & .02 & .07 & 1.02 & -.04 & .10 & .96 & .12 & .05 & $1.13^{*}$ \\
Recidivism & -.67 & .19 & $.51^{* * *}$ & -.15 & .10 & .86 & -.13 & .15 & .88 & -.22 & .09 & $.80^{* *}$ \\
Violent offending (1/0) & .38 & .40 & 1.47 & .28 & .37 & 1.32 & .35 & .48 & 1.42 & .74 & .37 & $2.10^{*}$ \\
\hline
\end{tabular}

Note. Reference group: Class 5 - very low levels of Criminal Social Identity, $B=$ estimate, OR = Odds Ratio, $S E=$ Standard Error. $* p<.05 ; * * p<.01 ; * * * p<.001$

\section{Discussion}

The primary purpose of the current study was to identity the appropriate number of latent classes of criminal social identity within a recidivistic criminal sample, and to test the association between class membership and age, number of police arrests, level of recidivism, and engagement in violent crime. In order to identify the appropriate number of distinct latent classes of criminal social identity, a latent class analysis was conducted on data from the MCSI (Boduszek et al., 2012) rom a large sample of recidivistic violent and non-violent incarcerated offenders.

Results from the LCA indicated the presence of five latent classes that were both quantitatively and qualitatively distinct. The baseline class (Class 5) was the 'Low-criminal social identity' groupand consisted of almost one-quarter of the sample. Individuals in this class were characterised by low endorsement of all items comprising the three components of criminal social identity. A slightly smaller but still substantial (17\%) 'High criminal social identity' class (Class 1) was identified which contained individuals characterised by displaying high levels of endorsement across all items measuring centrality, in-group affect, and in-group ties. Three intermediate classes also emerged from the analysis. The largest of these classes included individuals who displayed low levels of endorsement on items measuring both cognitive centrality and in-group ties, and high levels of endorsement on items measuring in-group affect (Class 4). Another relatively high-criminal social identity class was found, which contained individuals displaying high levels of endorsement on cognitivecentrality, more moderate levels of endorsement of in-group affect items, and low endorsement rates of the in-group ties items (Class 2). The final intermediate class, and also the smallest (Class 3), displayed the opposite profile to Class 2. These criminals displayed low levels of endorsement of the items measuring centrality, moderate levels of endorsement of the in-group affect items, and high levels of endorsement for the in-group ties items. These results strongly suggest that criminal social identify is not a dichotomous entity. Instead, the results suggest the presence of various subtypes 
of criminal social identity that criminals may well fall into. These subtypes may include profiles in which individuals display moderate or high levels of only one or two of the components of criminal social identity.

Multinomial logistic regression analysis was subsequently performed to estimate the relationship between latent class membership and age, number of police arrests, levels of recidivistic criminal behaviour, and engagement in violent offending. None of the four variables tested significantly predicted membership of the High Centrality, Moderate Affect, Low Ties class (Class 2), or the Low Centrality, Moderate Affect, High Ties class (Class 3 ), compared to the baseline Low-criminal social identity class (Class 5).

Having committed a violent offence and number of police arrests were found to be positively associated with belonging to the Low Cognitive, High Affect, Low Ties class (Class 4). A history of committing a violent criminal act was the strongest predictor with results indicating that an individual who had committed a violent act was slightly more than twice as likely to belong to this criminal social identity class as compared to those individuals who belonged to the Low-criminal social identity class of criminals. For every additional arrest a person experienced by the police, a person was just over one time more likely to belong to this class as compared to the Low-criminal social identity class. Interestingly, levels of recidivism were negatively associated with this class membership. This suggests that criminals who reoffend more frequently are less likely to belong to the Low Cognitive, High Affect, Low Tiesclass of criminals as compared to those in the Low-criminal social identity class.

Two of the four investigated variables were discovered to be significantly associated with belonging to the High-criminal social identity criminal social identity class. Numbers of police arrests were found to positively predict belonging to the High-criminal social identity class in a manner similar to the Low Cognitive, High Affect, Low Ties class. Again, in the case of the High-criminal social identity class, recidivism levels were negatively associated with membership of the High-criminal social identity class compared to the Low-criminal social identity class. This finding also indicates that increased frequency of criminal behaviour means that one is less likely to belong to the High-criminal social identity class compared to the Lowcriminal social identity class.

The finding that increased levels of recidivism was negatively associated with membership in the High-criminal social identity class or the class characterised by high levels of in-group affect, compared to the class displaying low levels of criminal social identity, was unexpected and somewhat surprising. Theoretically, it might be expected that more frequent engagement in criminal activity would be positively associated with a stronger criminal social identity. However, these results should be interpreted in relation to the nature of the sample that was used in the current analysis. Participants in the present research were all incarcerated prisoners in a maximum security unit. Although speculative at this point, it may be the case that for individuals who find themselves incarcerated for the first time, there is a need to display a strong criminal identity in order to adapt to one's surroundings and to form social relationships with other criminals. Alternatively, with repeated criminal offences and thus a greater amount of time spent in a prison environment, the need to actively display a criminal identity among the social group may become less important. This theoretical suggestion now awaits future empirical investigation.

Conclusions drawn from the current study must necessarily be considered in light of a number of limitations. First, the nature of the sample is limited to a very specific group of criminals; male recidivistic criminals incarcerated in a maximum security setting. Thus, it is replication of the current analysis with more diverse samples of criminals, such as female offenders, is clearly necessary. Additionally, participants were recruited from the Polish population, it is, therefore, unknown whether these results will generalise to samples drawn from alternative nationalities. Second, the analyses were based upon the use of self-report measures of criminal social identity (MCSI; Boduszek et al., 2012) which has not been subjected to extensive psychometric testing. Further establishment of the scale's construct validity would add considerably weight to any conclusions regarding the dimensionality of criminal social identity drawn from research using this new measure. Third, because the measures are based on prisoners' self-reports, it is impossible to ascertain with any degree of certainty whether some of the observed effects might be the consequence of response bias (i.e., socially desirable responding or intentional distortion of responses). However, this part of the study design could not be controlled by the researchers conducting such a project with recidivistic prisoners. Finally, many of the wider societal and psychological factors that might contribute towards criminal social identity were not able to be explored within the present study, such as the effect of criminal peer associations (Bourke, Boduszek, \& Hyland, 2013), self-esteem (Boduszek et al., 2012), personality (Boduszek et al., 2013c), psychopathy (Dhingra \& Boduszek, 2013), and criminal thinking styles (Boduszek et al., 2013b). Consequently, future research would benefit from considering the relationship between each of these factors and criminal social identity group membership. Future work is also needed to identify whether these distinct classes of criminal social identity predict engagement in various types of criminal behaviour.

In conclusion, this study suggests that the latent structure of criminal social identity consists of five distinctsub groups that display qualitative and quantitative differences. It was notable that, although all classes differed either qualitatively or quantitatively from the Low-criminal social identity comparison group, levels of recidivism, number of police arrests, and a history of engaging in violent offences were only able to predict membership of either the High-criminal social identity class or the Low Cognitive, High Affect, Low Ties class. This suggests the need to examine a range of other psychological and sociodemographic factors that may explain class membership. The results of this study have also suggested a new 
development to the theory of criminal social identity with respect to the nature of recidivism. Future work is necessary to ascertain the true nature of this relationship, as well to identify whether these distinct classes of criminal social identity present differential risk-factors for engagement in various types of criminal behaviour. In general, this study reveals much about the different levels of criminal social identity that exist among the criminal population, as well as identifying critical factors in predicting criminal social identity. The current study consequently adds important and original evidence to the emerging literature on the nature and predictors of criminal social identity.

\section{References}

Allport, G. W. 1979. The Nature of Human Prejudice. London: Basic books.

Baumeister, R. F., \& Leary, M. R. 1995. The need to belong: desire for interpersonal attachments as a fundamental human motivation. Psychological Bulletin, 117: 497-529.

Boatswain, S. J., \& Lalonde, R. N. 2000. Social identity and preferred ethnic/racial labels for Blacks in Canada. Journal of Black Psychology, 26:216-234

Boduszek, D., Adamson, G., Shevlin, M., Hyland, P., \& Bourke, A. 2013a The Role of Criminal Social Identity in the Relationship between Criminal Friends and Criminal Thinking Style within a Sample of Recidivistic Prisoners. Journal of Human Behavior in the Social Environment, 23:14-28.

Boduszek, D., Adamson, G., Shevlin, M., Mallett, J., \& Hyland, P. 2013b. Criminal Social Identity of Recidivistic Prisoners: The Role of Self-Esteem, Family and Criminal Friends. Journal of Police and Criminal Psychology, 1-11.

Boduszek, D., Shevlin, M., Adamson, G., \& Hyland, P. 2013c. Eysenck's Personality Model and Criminal Thinking Style within a Violen and Nonviolent Offender Sample: Application of Propensity Score Analysis. Deviant Behavior, 34:483-493.

Boduszek, D., Hyland, P., Bourke, A., Shevlin, M., \& Adamson, G. 2013d Assessment of psycho-social factors predicting recidivistic violent offenses within a sample of male prisoners. The Irish Journal of Psychology, 34:24-34.

Boduszek, D., Adamson, G., Shevlin, M., Mallett, J., \& Hyland, P. (2013e) Criminal Social Identity of Recidivistic Prisoners: The Role of Self-Esteem, Family and Criminal Friends. Journal of Police and Criminal Psychology, 1-11.

Boduszek, D., Adamson, G., Shevlin, M., \& Hyland, P. 2012. Development and validation of a measure of criminal social identity within a sample of polish recidivistic prisoners. Criminal Behaviour and Mental Health, 22:315-324.

Boduszek, D., \& Hyland, P. 2011. The theoretical model of crimina social identity: Psycho-social perspective. International Journal of Criminology and Sociological Theory, 4:604-615.

Bourke, A., Boduszek, D., \&Hyland, P. 2013. The role of crimina cognitions and personality traits in non-violent recidivism: Empirical investigation within a prison sample. Journal of Criminal Psychology. 3: $10-48$.

Breakwell, G.M. 1986. Coping with threatened identities. London: Methuen.

Brown, R., Condor, S., Mathews, A., Wade, G., \& Williams, J. 1986. Explaining intergroup differentiation in an industrial organization. Journal of Occupational Psychology, 59:279-304.

Cameron, J. 2004. A three-factor model of social identity. Self and Identity, 3:239-262.

Cameron, J. E., \&. Lalonde, R.N. 2001. Social identification and genderrelated ideology in women and men. British Journal of Social Psychology 40: 59-77.

Dhingra, K., \& Boduszek, D. 2013. Psychopathy and Criminal Behaviour: A Psychosocial Research Perspective. Journal of Criminal Psychology, 3: 83-107.

Ellemers, N., Kortekaas, P., \& Ouwerkerk, J. 1999. Self-categorisation, commitment to the group and group self-esteem as related but distinct aspects of social identity. European Journal of Social Psychology,
29: 371-289.

Gurin, P., \& Markus, H. 1989. Cognitive consequences of gender identity. In The social identity of women, edited by S. Skevington \& D. Baker (Eds.). London: Sage.

Higgins, E. T. 1987. Self-discrepancy: A theory relating self and affect. Psychological Review, 94:319-340.

Hinkle, S., Taylor, L., Fox-Cardamone, D., \& Crook, K. 1989. Intragroup identification and intergroup differentiation: A multicomponent approach. British Journal of Social Psychology, 28:305-317.

Klein, M. W., \& Crawford, L. Y. 1967. Groups, gangs, and cohesiveness. Journal of Research in Crime and Delinquency, 4:63-75.

Lemyre, L., \& Smith, P. M. 1985. Intergroup discrimination and selfesteem in the minimal group paradigm. Journal of Personality and Social Psychology, 49:660-670.

Losel, F. 2003. The development of delinquent behaviour. In Handbook of Psychology in Legal Context (2nd Ed.), edited by D Carson and R Bull. England: John Wiley and Sons, Ltd.

Luhtanen, R., \& Crocker, J. 1992. A collective self-esteem scale: Selfevaluation of one's social identity. Personality and Social Psychology Bulletin, 18:302-318.

Matza, D. 1964. Delinquency and Drift. New York: Wiley.

Mills, J. F., Anderson, D., \&Kroner, D. G. 2004. The antisocial attitudes and associates of sex offenders. Criminal Behaviour and Mental Health, 14:134-145.

Mills, J. F., Kroner, D. G., \& Forth, A. E. 2002. Measures of Criminal Attitudes and Associates (MCAA) Development, Factor Structure, Reliability, and Validity. Assessment, 9:240-253.

Mills, J. F., Kroner, D. G., \& Hemmati, T. 2004. The Measures of Criminal Attitudes and Associates (MCAA) The Prediction of General and Violent Recidivism. Criminal Justice and Behavior, 31:717-733.

Muthen, L.K., \& Muthen, B.O. 1998-2010. Mplus - Statistical Analysis with Latent Variables. User's Guide (6th ed.). Muthen \& Muthen: Los Angeles.

Obst, P., Smith, S. G., \& Zinkiewicz, L. 2002. An exploration of sense of community, Part 3: Dimensions and predictors of psychological sense of community in geographical communities. Journal of Community Psychology, 30:119-133.

Oakes, P. J., \& Turner, J. C. 1980. Social categorization and intergroup behaviour: Does minimal intergroup discrimination make social identity more positive? European Journal of Social Psychology, 10:295-301.

Pabon, E., Rodriguez, O. and Gurin, G. 1992. Clarifying peer relations and delinquency. Youth and Society, 24:149 -165.

Phinney, J. 1992. The Multigroup Ethnic Identity Measure: A new scale for use with adolescents and young adults from diverse groups. Journal of Adolescent Research, 7:156-176.

Sellers, R. M., Rowley, S. A., Chavous, T. M., Shelton, J. N., \& Smith, M. A. 1997. Multidimensional Inventory of Black Identity: Preliminary investigation of reliability and construct validity. Journal ofPersonality and Social Psychology, 73:805-815.

Sutherland, E. H., Cressey, D. R., \& Luckenbill, D. F. 1992. Principles of criminology. Rowman \& Littlefield.

Sutherland, E., Cressey, D., \& Luckenbill, D. 1978. Principles of criminology. General Hall. Dix Hills, NY.

Sykes, G. M., \& Matza, D. 1957. Techniques of neutralization: a theory of delinquency. American Sociological Review, 22:664-670.

Tajfel, H. 1978. Differentiation between Social Groups: Studies in the Social Psychology of Intergroup Relations. London: Academic Press.

Tajfel, H., \& Turner, J. 1979. An integrative theory of intergroup conflict. In The social psychology of intergroup relations, edited by W. Austin and S. Worchel (Eds.). Monterey, CA:Brooks/Cole.

Thornberry, T., Krohn, M., Lizotte, A., \& Chard-Wierschem, D. 1993. The Role of Juvenile Gangs in Facilitating Delinquent Behavior. Journal of Research in Crime and Delinquency, 30:55-87.

Turjeman, H., Mesch, G., \& Fishman, G. 2008. The effect of acculturation on depressive moods: Immigrant boys and girls during their transition from late adolescence to early adulthood. International Journal of Psychology, 43:32-44.

Turner, J. C. 1982. Towards a cognitive redefinition of the social group. In Social Identity and Intergroup Relations, edited by H. Tajfel (Ed.). Cambridge: Cambridge University Press.

Turner, J. C., Hogg, M. A., Oakes, P. J., Reicher, S. D., \& Wetherell, M. S. 1987. Rediscovering the social groups: A self-categorization theory. Oxford: Blackwell 